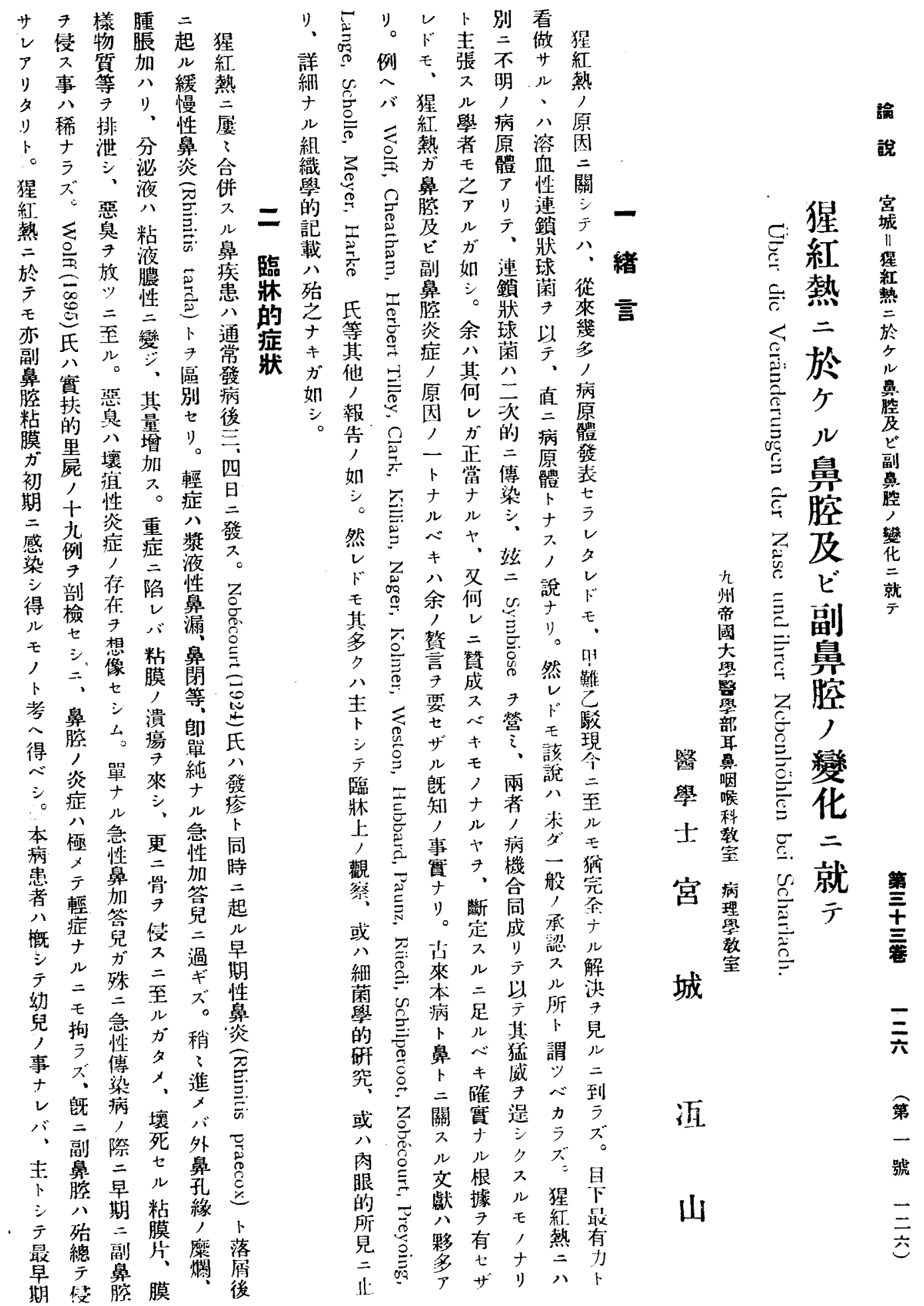




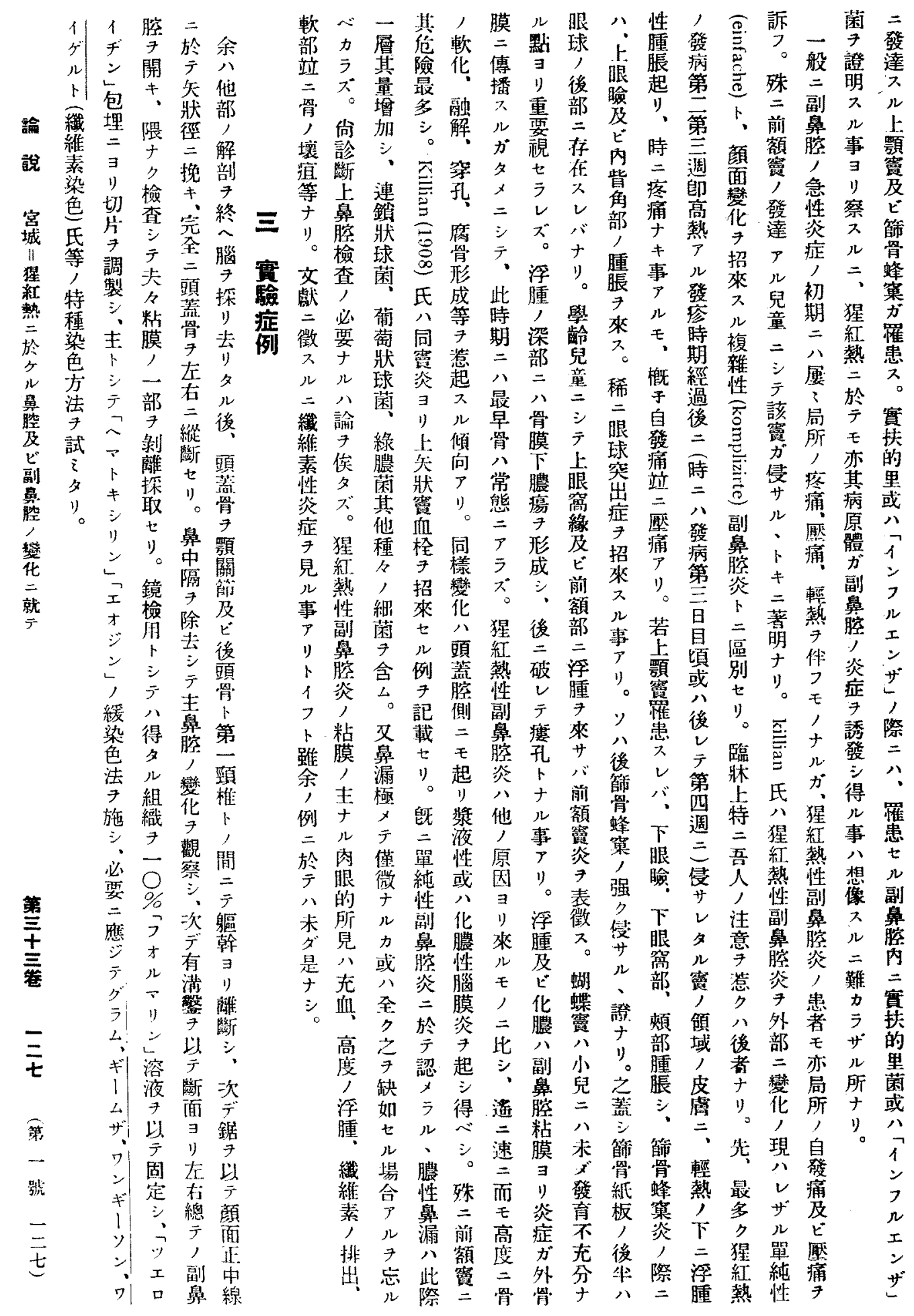




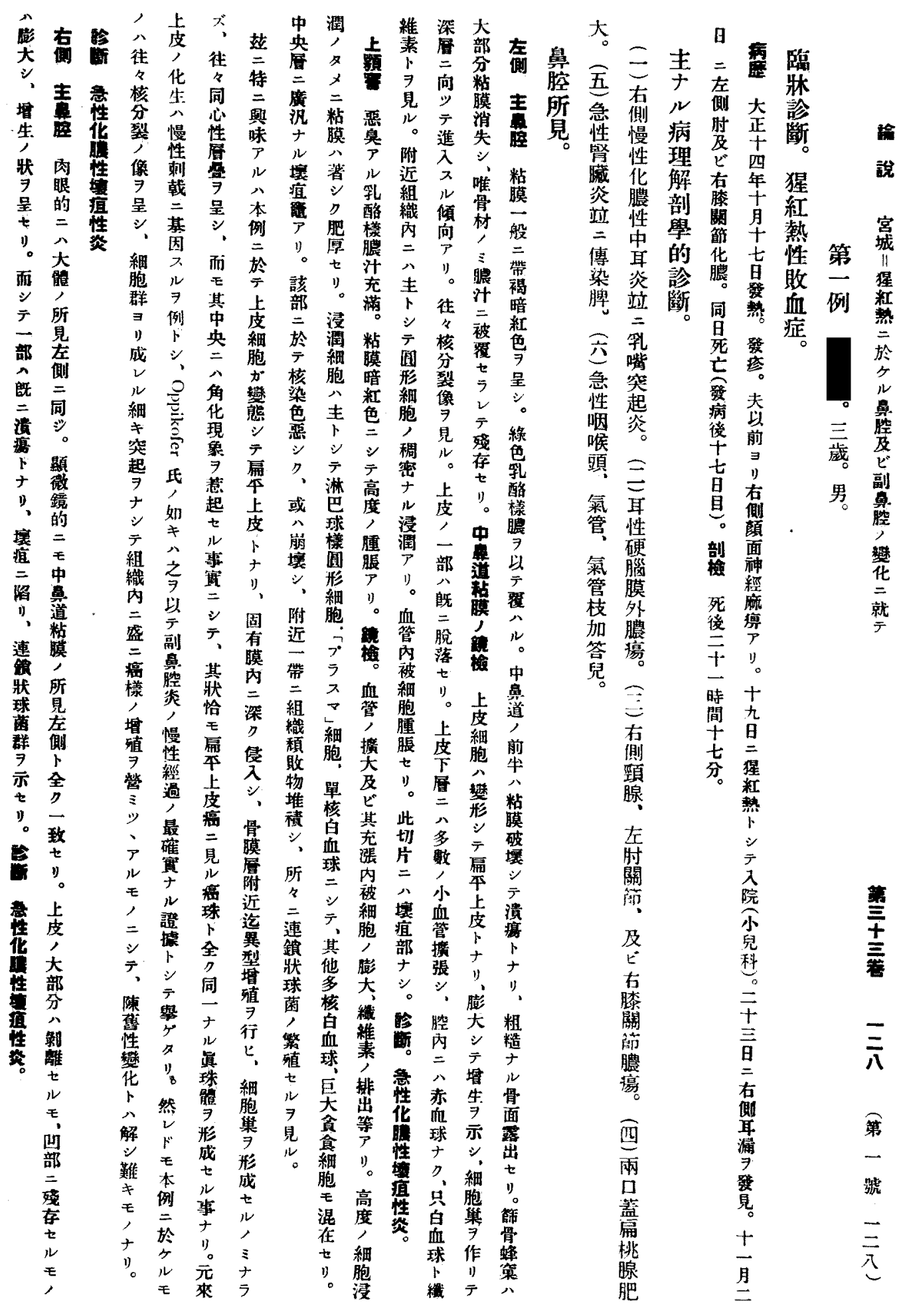




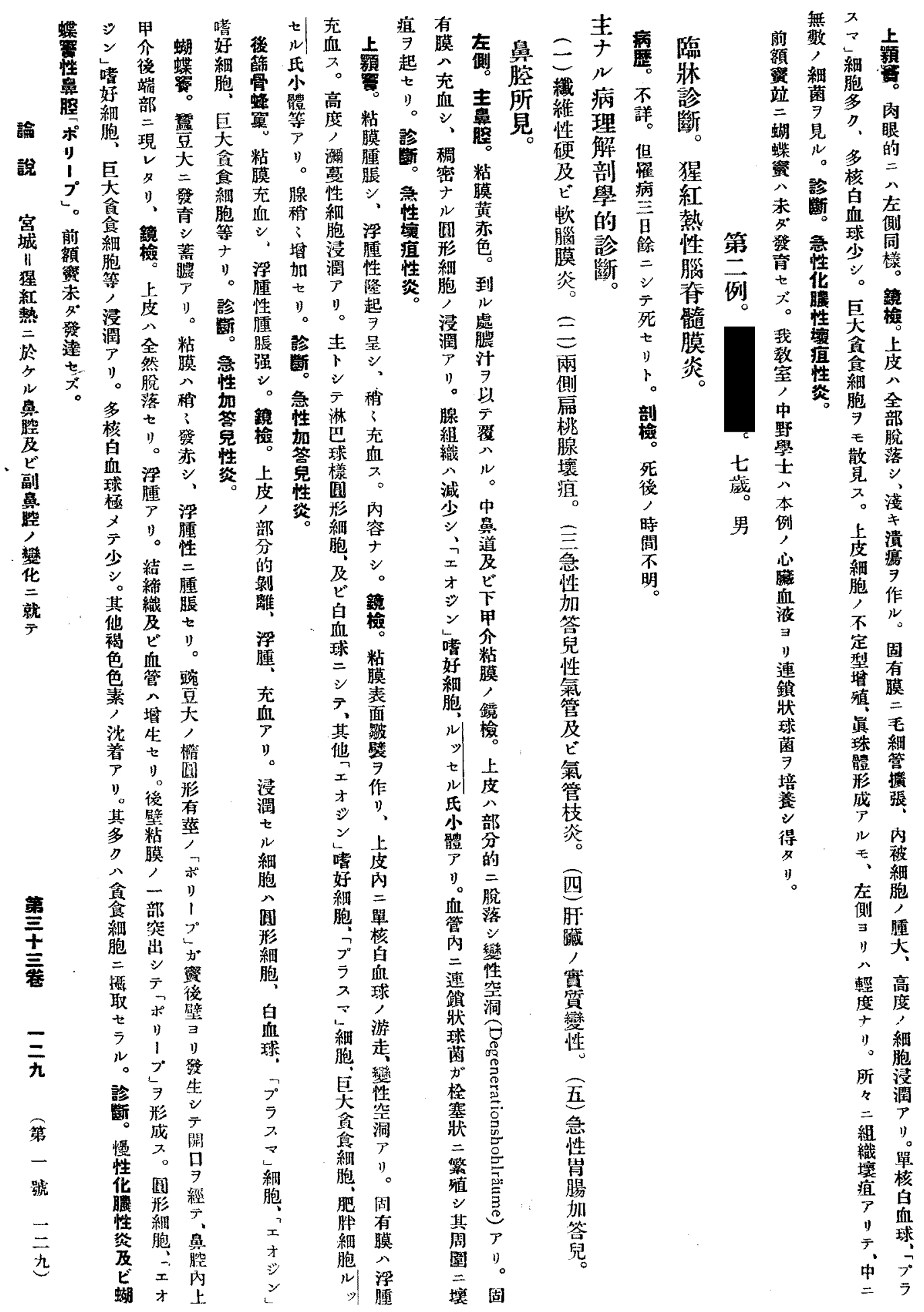




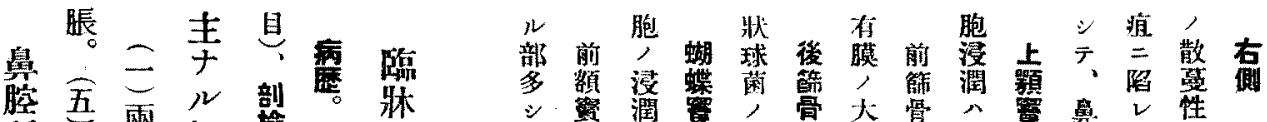

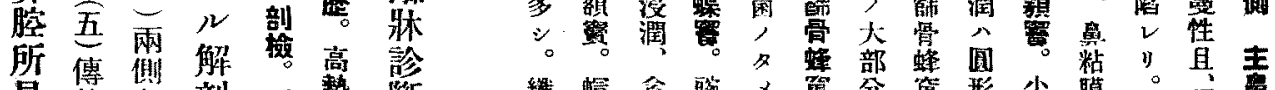

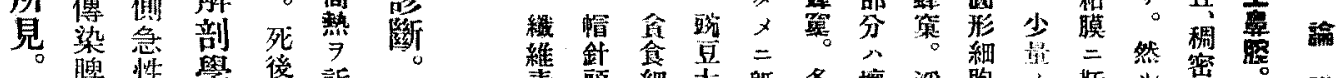

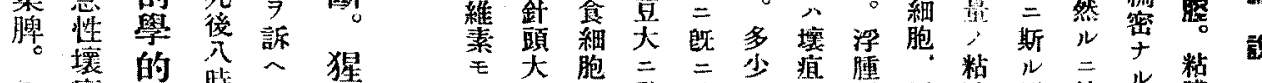

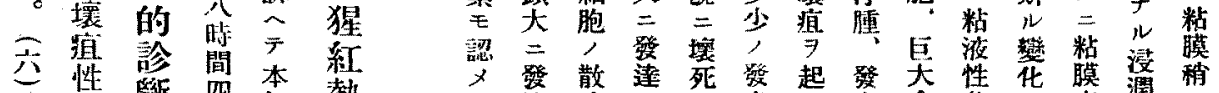

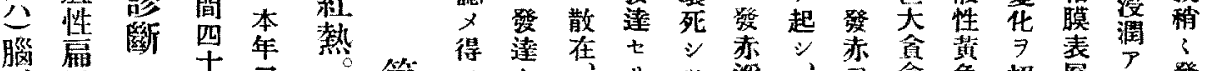

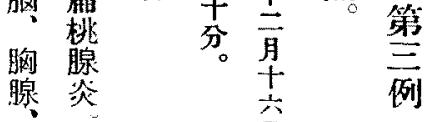

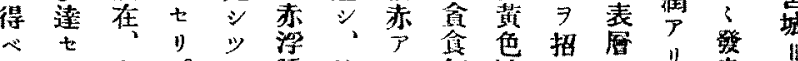

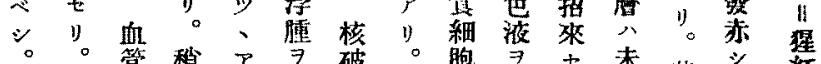

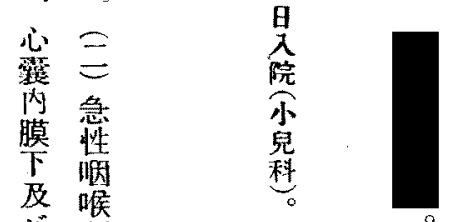

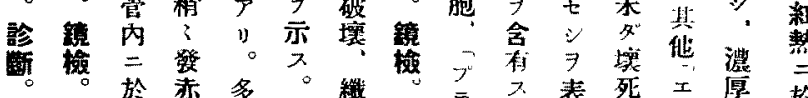

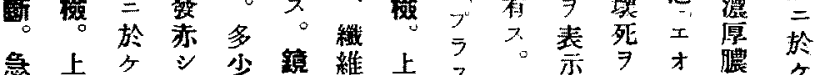

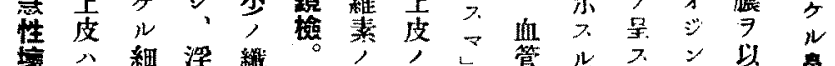

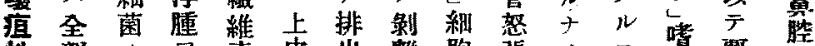

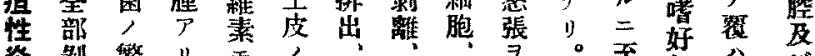
ビ 頭 胁氣

崥 放

出 加

血答

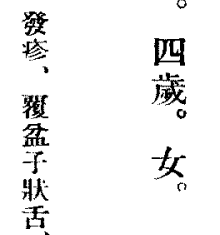

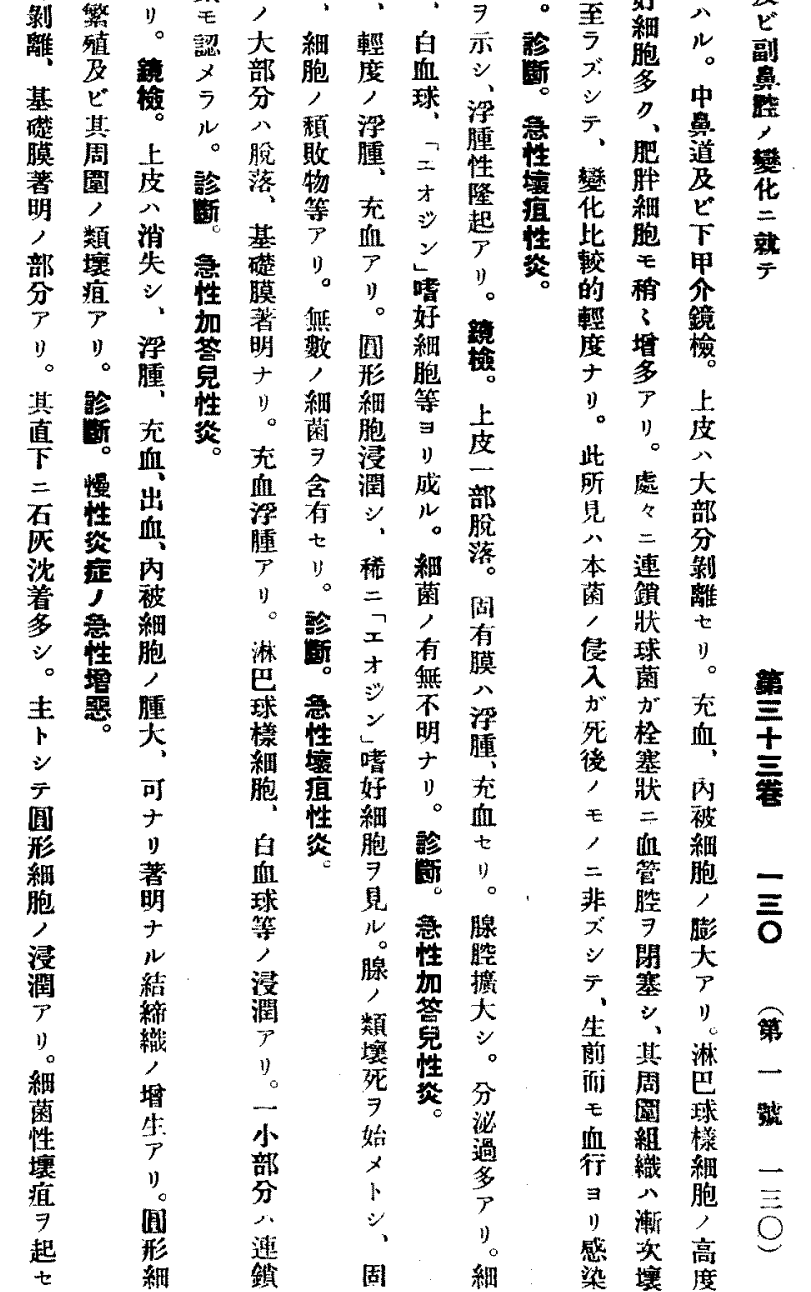




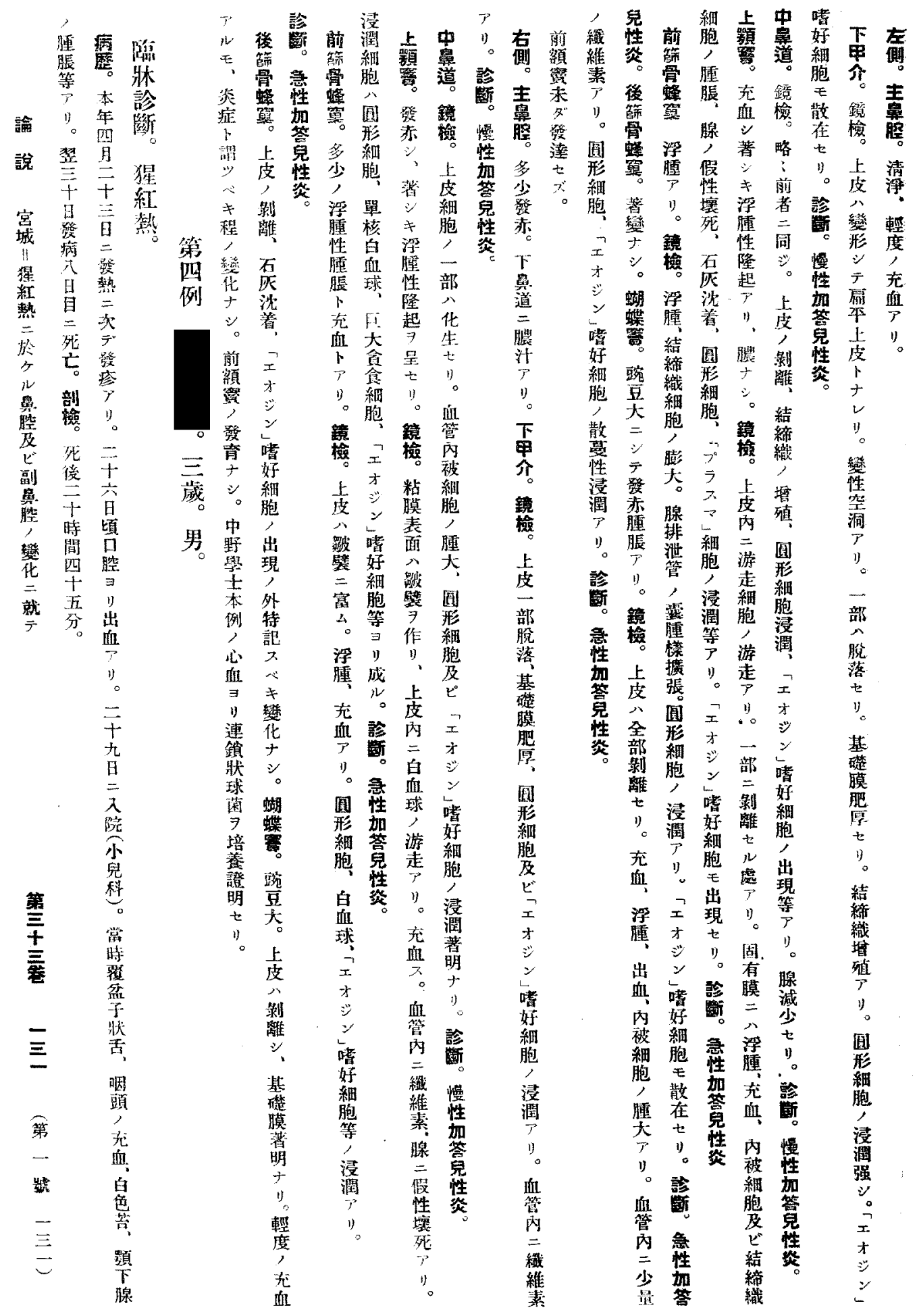




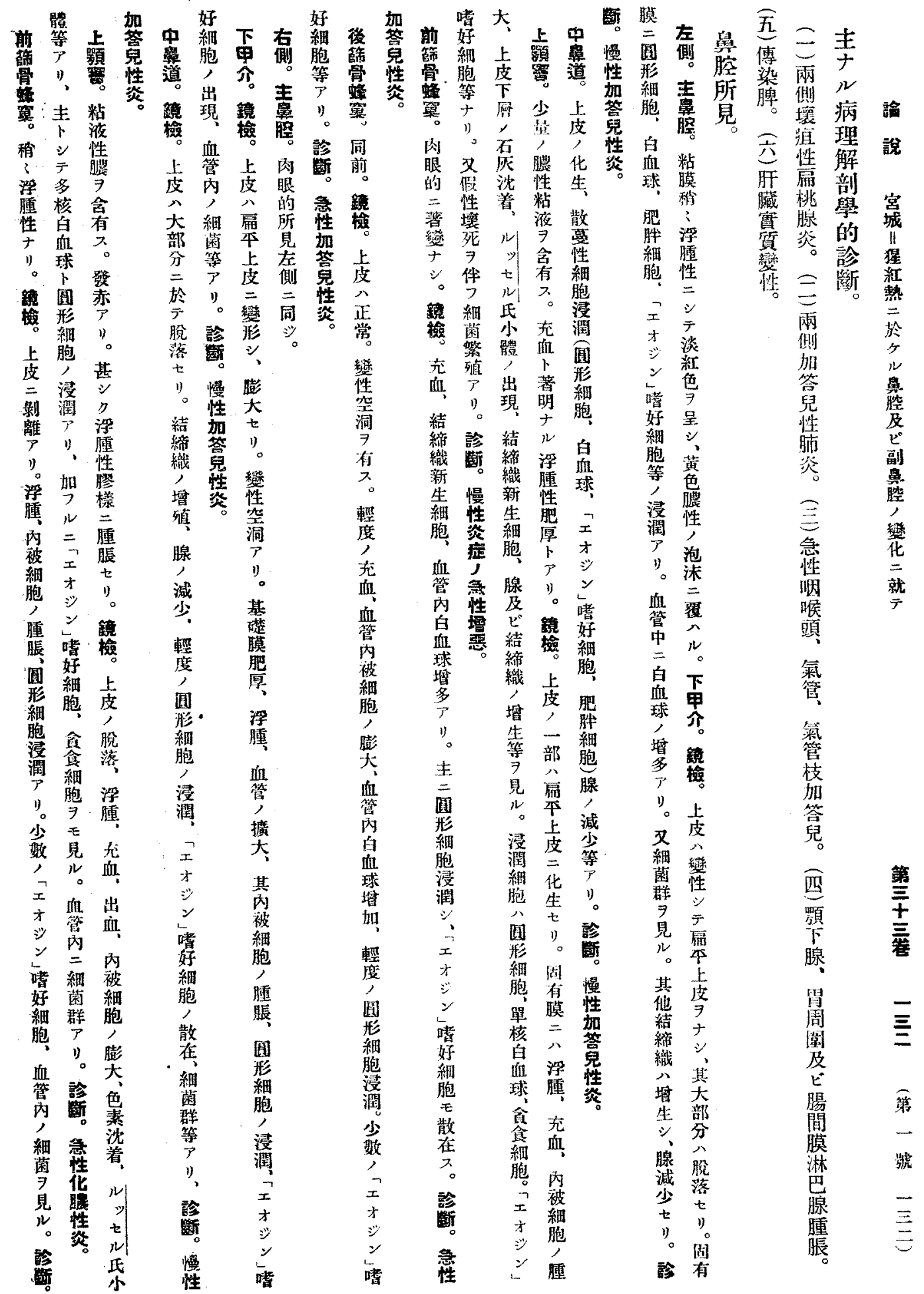




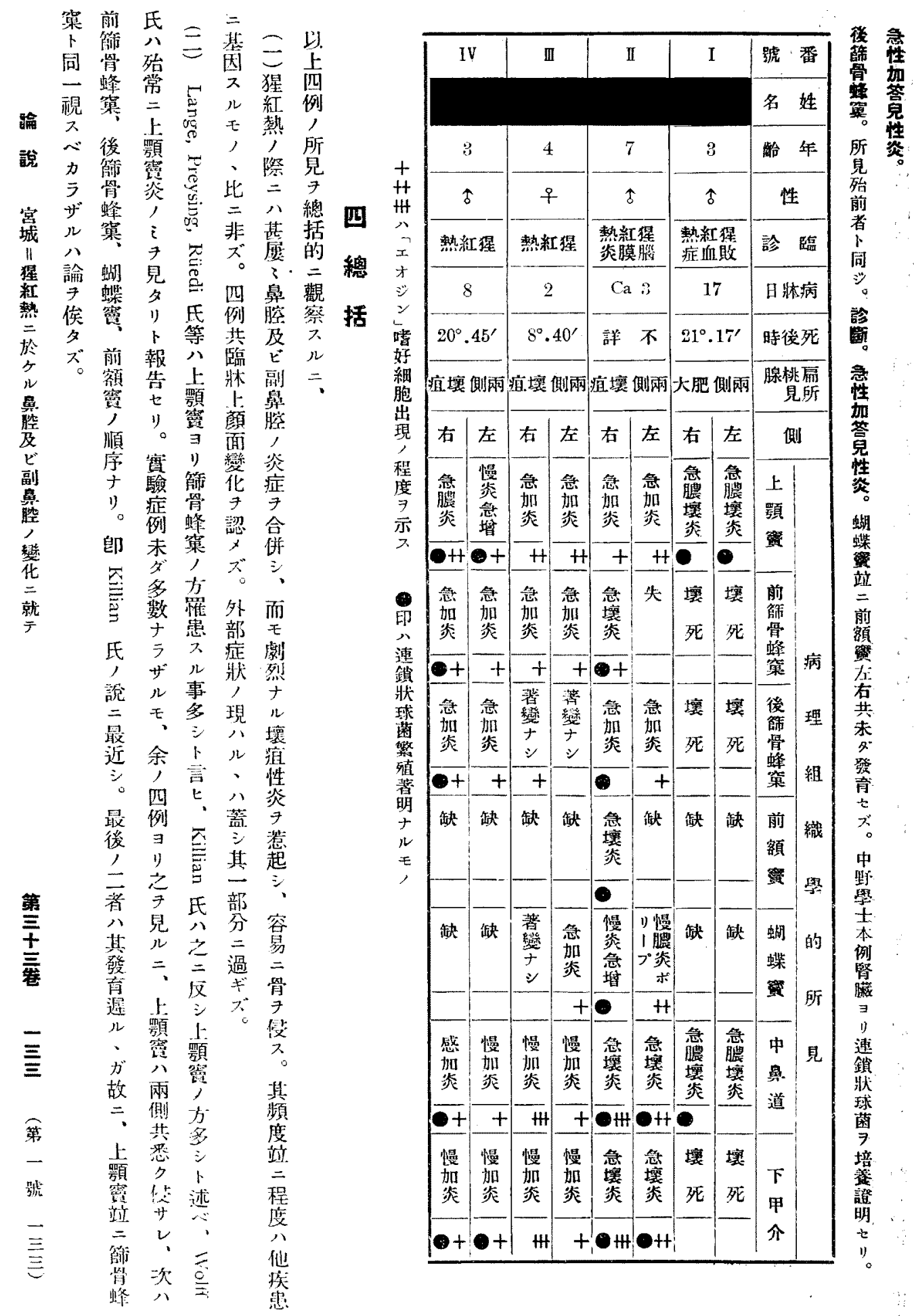




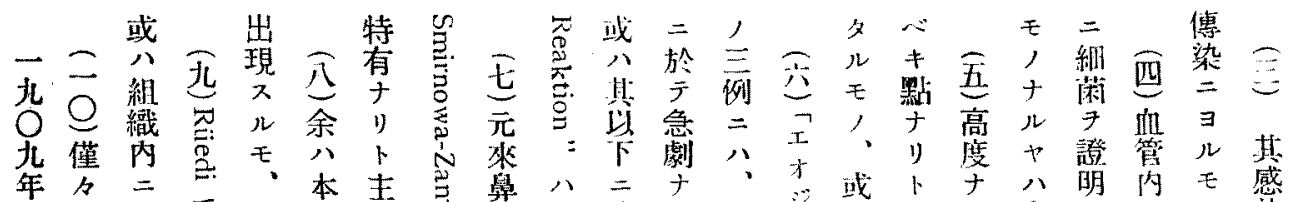

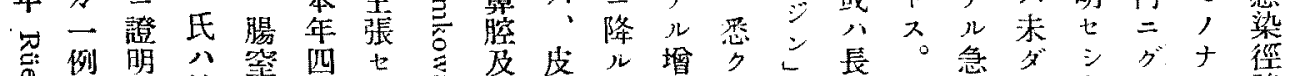

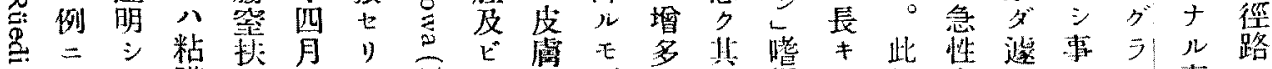

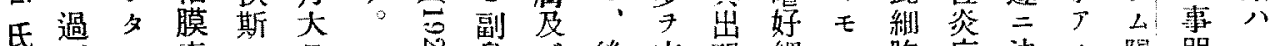
氏荡 猩 熱 $モ$ 繊 血 特 鼻 經、維管著喉 細素二等

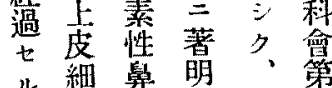

ル胞竾ナ副第

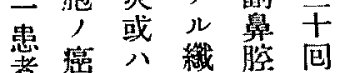
者䇰副維二總

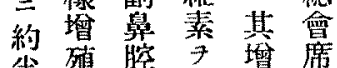

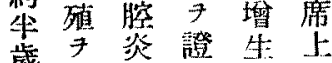
歲見炎明等三 再多稱三、見於 器儿え゙猩旨卢 香興 $\neq$ 縕 $尹$

行味程热報 舍

行深度性告 食 $シ \neq 三$ 瀻七 緗 二所顯維 ”。胞 見著素。父

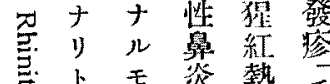
泀下, 资熱手

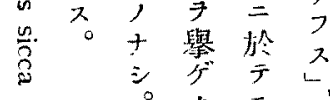

(a)

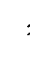

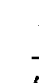

例 多走赤 公痢

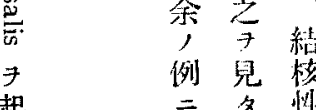

起方多柆

夕)

耖

蕔 于 = 多

毛华謷殊

如气炎僡現》現则

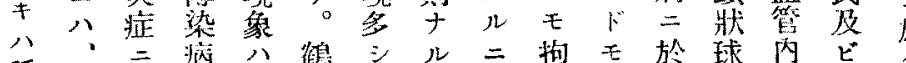

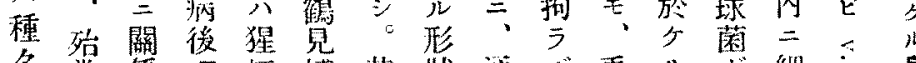

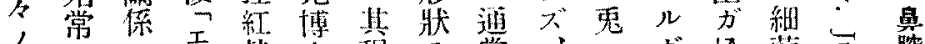

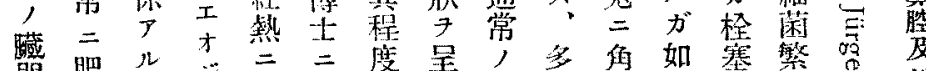

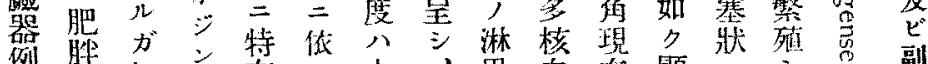
例盟如之有乞本・巴白在顯二シ 副

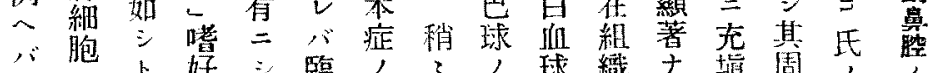

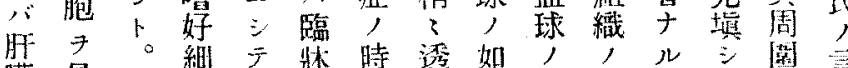

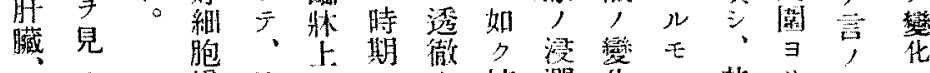

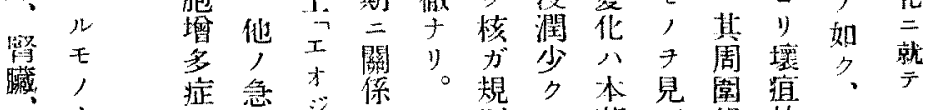

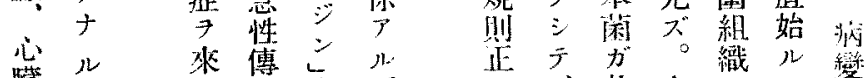

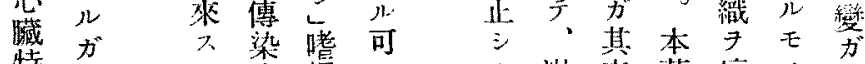

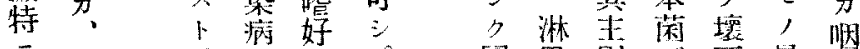

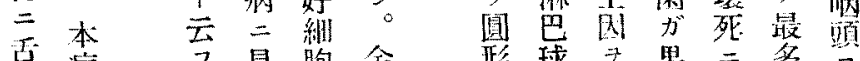
点病 ᄀ見胞余形球

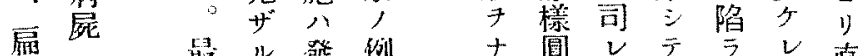

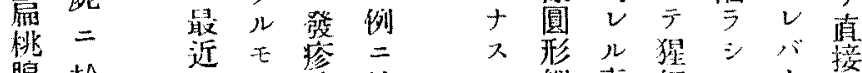

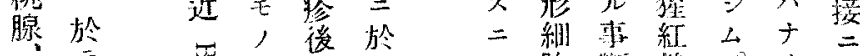

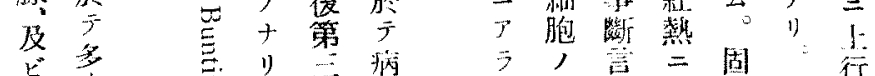

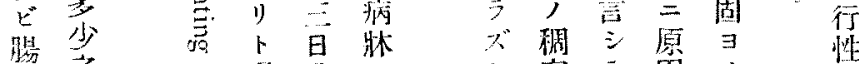

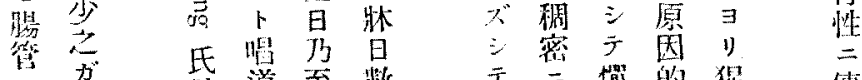

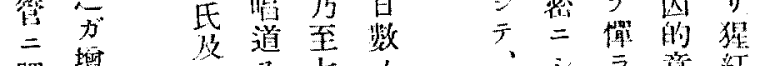

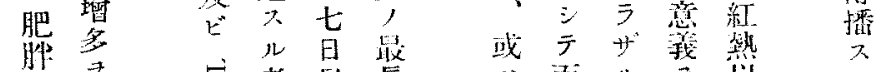

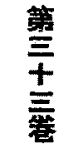

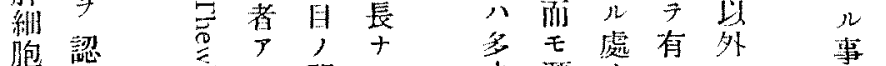

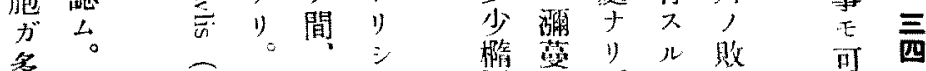

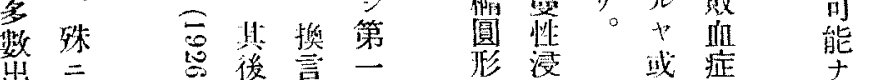

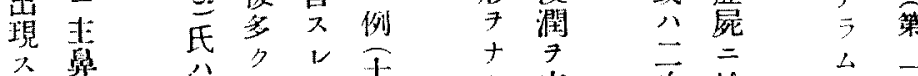

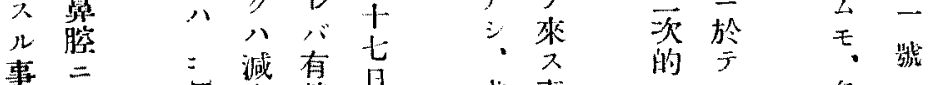

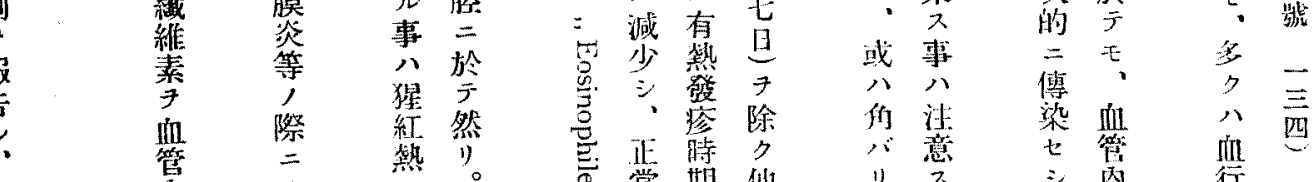




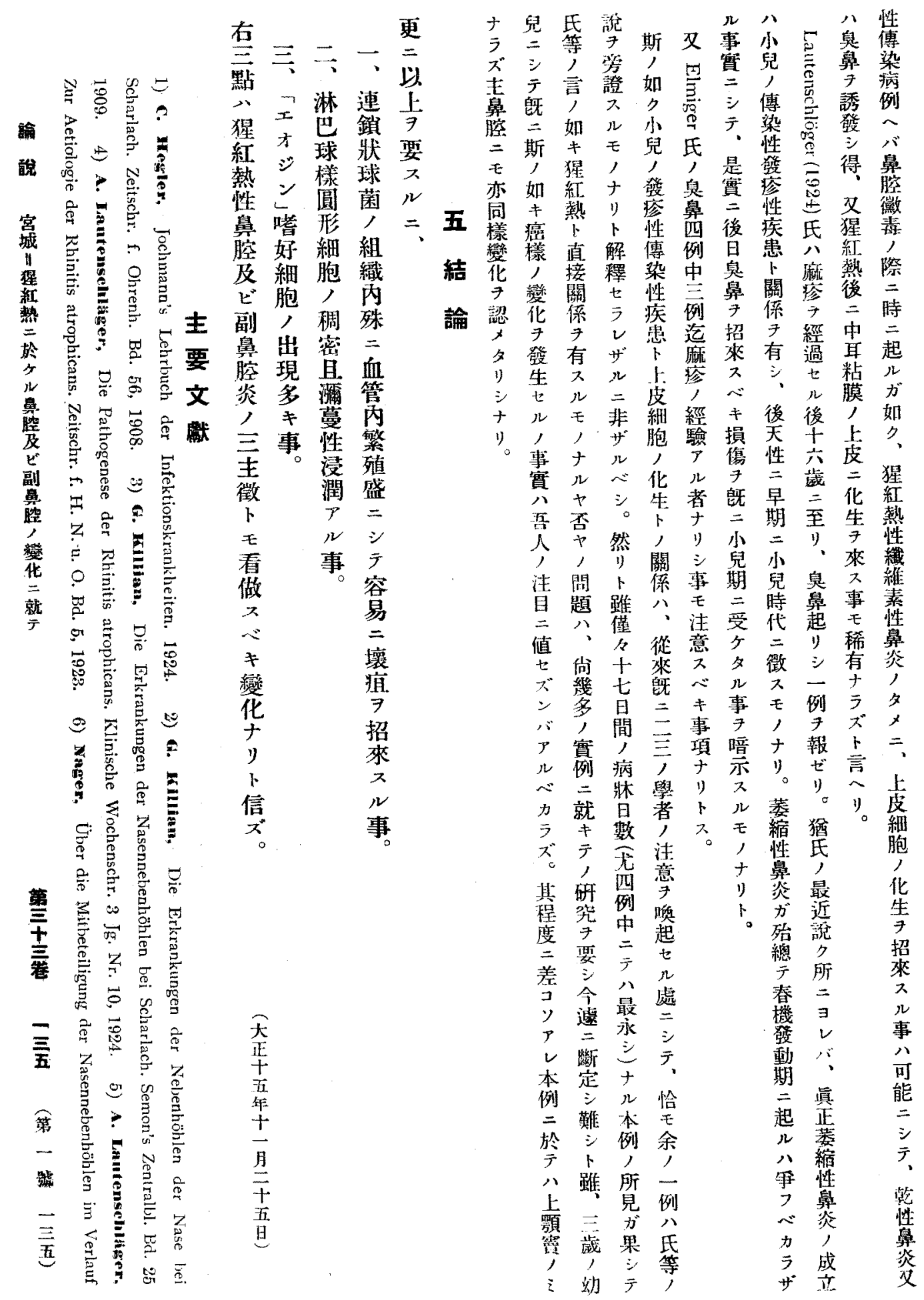




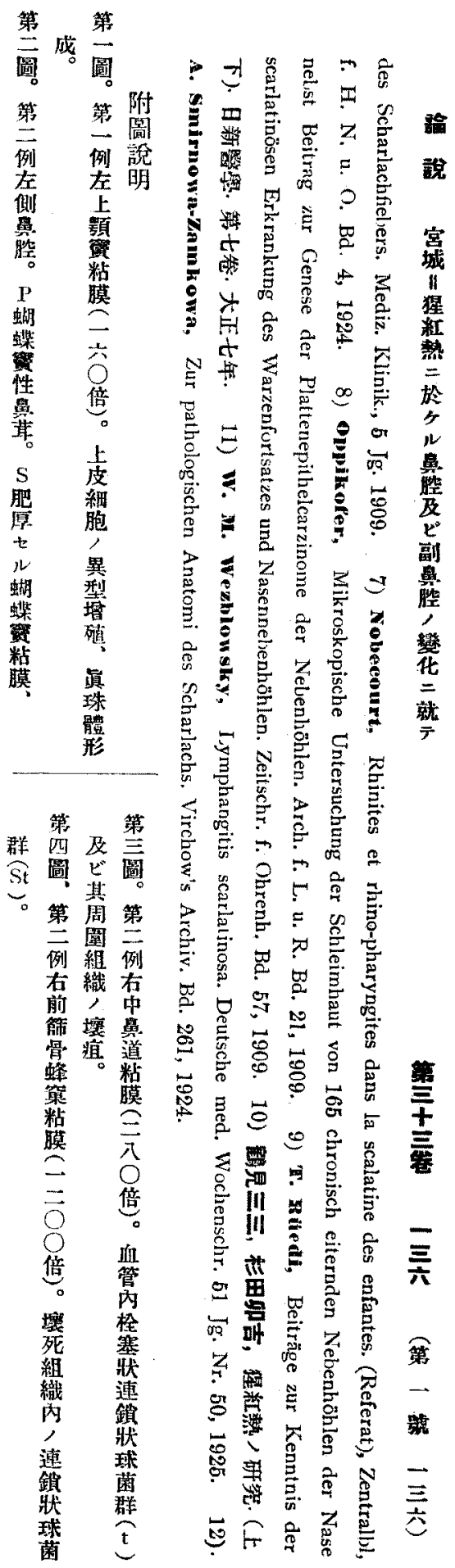



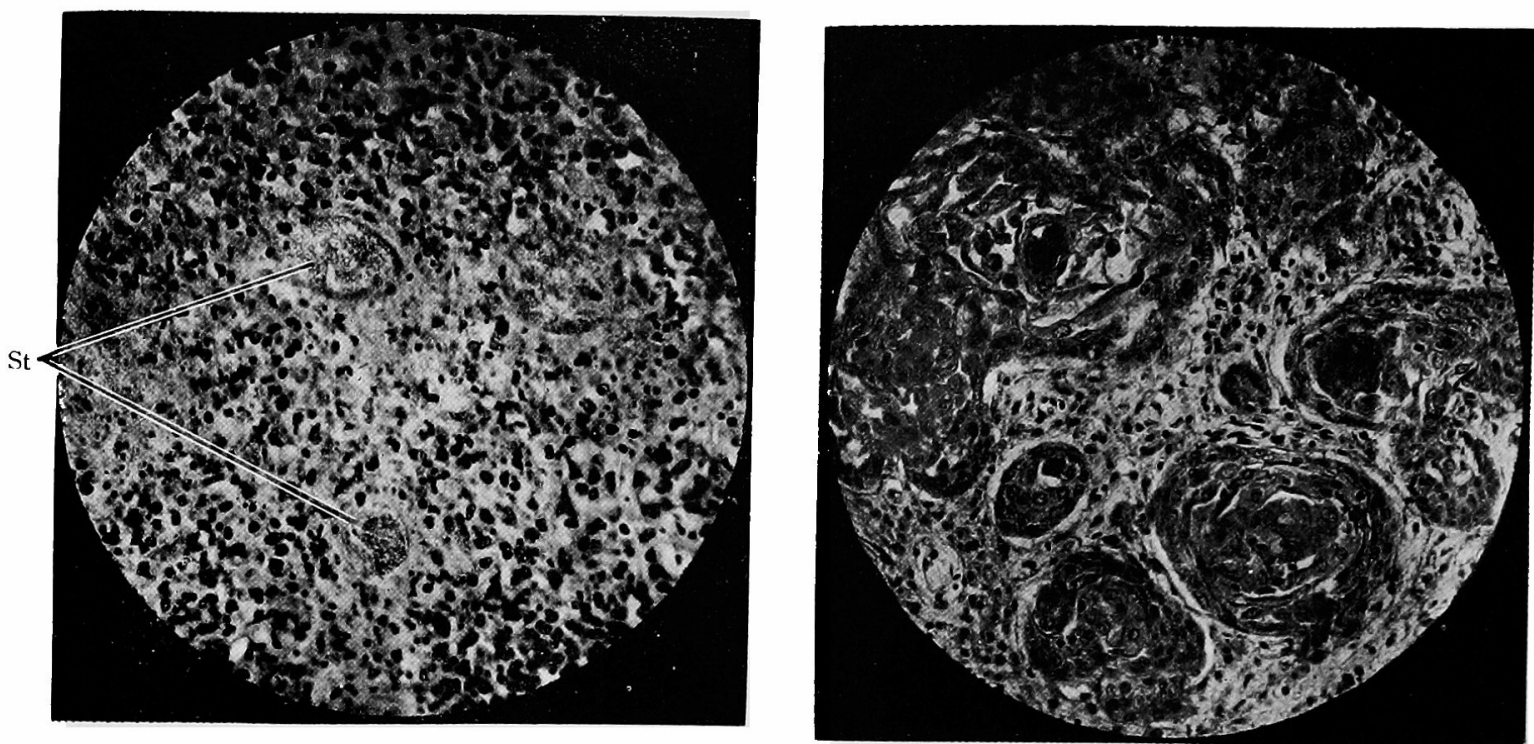

Fig. 4

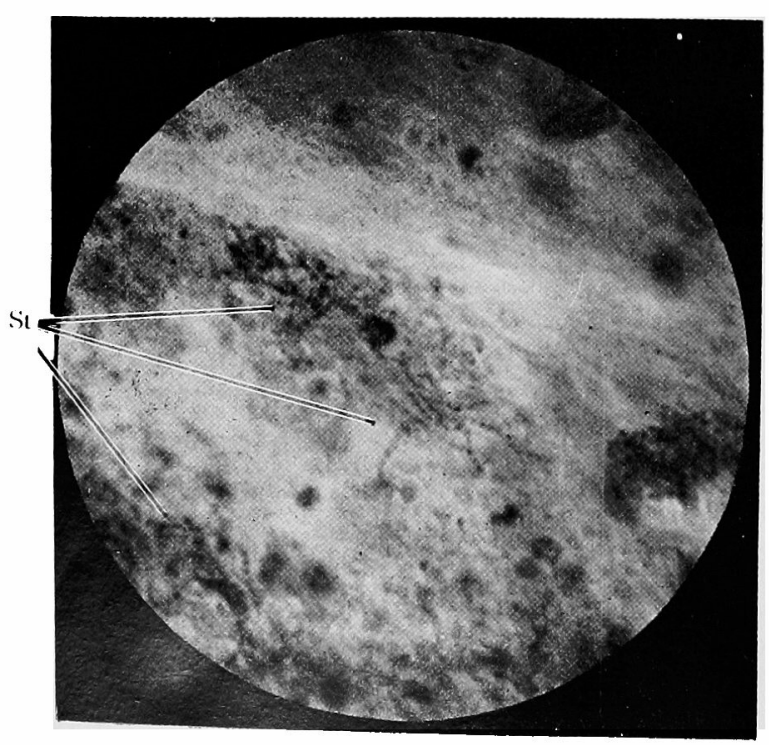

Fig. 2

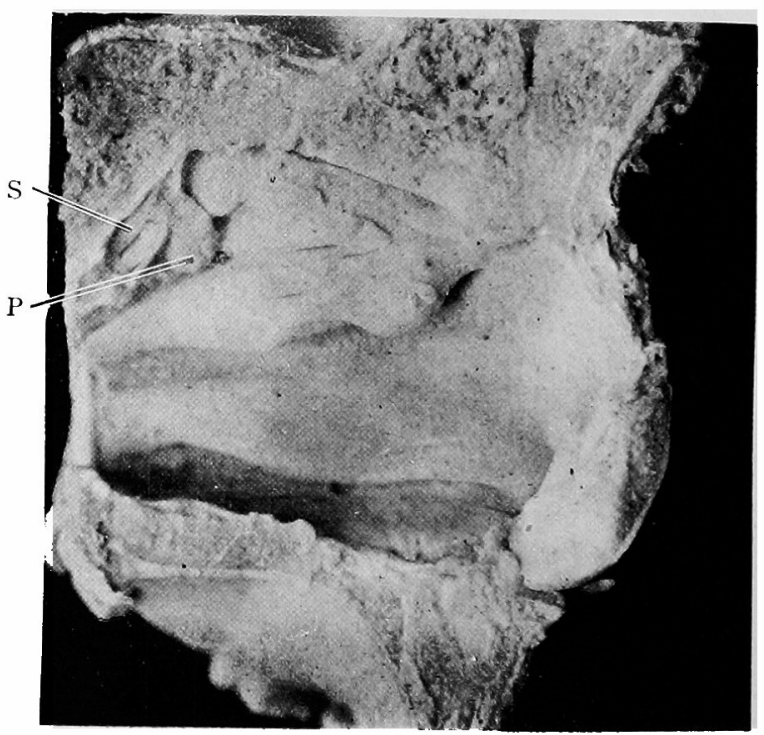




\title{
Die obere Hörgrenze der Japaner festgestellt mit dem Struyckenschen Monochord.
}

Von

\author{
Dr. Ryuichi Matsuda.
}

(Aus d, oto-, rhino-, laryngologischen Institut der Universität zu Tokio.)

Verfasser hat an Japanern über die Wahrnehmung höchster Töne durch Luftund Knochenleitung mittels des Struyckenschen Monochords Untersuchungen angestellt.

(Autoreferni.)

\section{Über die Veränderungen der Nase und ihrer Nebenhöhlen bei Scharlach.}

Von

\author{
Dr. G. Miyagi.
}

(Aus der Universitäts- Ohren-, Nasen-u. Hals-Klinik (Direktor: Prof. Dr. Ino. Kubo.) u. dem Pathologischen Institut (Vorstand: Prof. Dr. H. Nakayama.), Fukuoka, Japan.)

Durch Schädelobduktion 4 Fällen kindlicher Scharlachleichen hat Verf. die Veränderungen der Nase und deren Nebenhöhlen histopathologisch genau untersucht und ist zur folgenden Zusammenfassung gekommen.

1. Bei Scharlach sind die Nasenhöhle und die Nebennasenhöhlen fast stets miterkrankt und zwar findet man äusserst heftige nekrotisierende Entzündung, die leicht zu kariösen Prozessen am Knochen neigt.

2. Am häufigsten sind die Kieferhöhlen beteiligt, dann folgen die vorderen Siebbeinzellen, hinteren Siebbeinzellen, Keilbeinhöhlen und Stirnhöhlen.

3. Die Infelition findet bei der Mehrzahl der Fälle auf dem Blutweg statt.

4. In den Gefassen, deren Umgebung schon der Nekrose anheimgefallen ist, konstatiert man auffallende embolische Ansiedelung einer Art von Streptokokken. Es ist kaum zu bezweifeln, dass die Streptokokken für die Gewebsveränderungen eine grosse Rolle spielen.

5. Die Infiltrate in der Schleimhaut bei Scharlach werden aus sehr dichten 
liegenden und diffusen verbreiteten lymphocytenartigen Rundzellen gebildet.

Trotz akuter und hochgradiger Entzündung sind polynucleäre Leucoyten meist nur spärlich. zu finden.

6. Das Erscheinen eosinophiler Zellen und Vermehrung (mehr oder weniger) der Mastzellen besonders in der Haupthöhle sind bemerkenswert.

7. Einen weiteren interessantern Befund bildet eine atypische karzinomatöse Wucherung der metaplasierten Epithelzellen bei einem 3 jährigen Kind.

(Autorfforat)

\title{
Über die klinischen Beziehungen der Zähne zu der Nase.
}

\author{
Von \\ Assistentprof. Dr. 'T. Isii. \\ Aus der oto- rhino- laryngologischen Universitătsklinik zu Nagoya. \\ (Direktor: Prof. Dr. B. Yagisawa.)
}

INDEX.

I. Teil. Über die Krankheiten der Nasen- und Highmorshöhle sowie des Oberkieferknochens infolge von Zahnerkrankungen.

II. Teil. Über die Stellungsanomalien der Zähne des Oberliefers.

III. Teil. Über die odontogenen Geschwülste.

\section{Teil. Über die Krankheiten eer Nasen- und Highmorshöhle sowie des Oberkieferknochens infolge von Zahnerkrankungen.}

Es ist bekannt, dass Krankheiten der Zähne bzw. Periodontitis häufig Krankheiten der Nasen- und Kieferhöhle sowie des Oberkieferknochens verursachen. Über diese zwei getrennten Spezialfächern gehörenden Krankheiten hat man ein wenig richtiges Urteil:

.Fall 1. 48 j. Mann. Subperiostaler Abszess des Nasenbodens infolge Alveolarknochennekrose des linken zweiten Schneidezahnes. Inzision und Auskratzung von Mundvorhofe, dann Extraktion des betreffenden Zahnes. Ausgeheilt.

Fall 2. 34 j. Frau. I.nke Kieferhöhleneiterung infolge Periodontitis des linken 